\title{
Performance Analysis of Jet Engine of Aircraft
}

\author{
N. Lenin Rakesh, Sabarish R, S. Karthikeyan
}

\begin{abstract}
The jet engine family includes the rocket jet, pulse jet, ram jet \& gas turbine powered jet. The gas turbine powered jet is further broken down into the turbo jet, turbo propeller, and turbo shaft \& turbofans types. These four types of engines are the most commonly used in today's aircraft. Kiran aircraft is the basic jet trainer used in Indian air force. Kiran MkII is fitted with Orpheus engine. The engine is a straight flow turbo jet type fitted with a seven stage axial flow compressor and develops $4200+-84 \mathrm{lbs} /$ $1909+-38 \mathrm{~kg}$ static thrust at $9500 \mathrm{rpm}$ at sea level. This increase to a maximum at 10,000 ft, due to the characteristics of high pressure fuel pumps in the engine fuel system. Above this height the thrust developed reduces as altitude increases. Air at atmospheric pressure is compressed adiabatically, during its passage across the compressor and diffuser, to approx $4 \mathrm{~atm}$. The pressure and temperature increases and volume decreases at this stage. In the combustion chamber it is supplied at constant pressure thereby considerably increasing the volume of the air. Then during passage of the gas stream through the rear end of the combustion chamber, stationary vanes, turbine and exhaust cone, there is adiabatic expansion which is completed in the propelling nozzle with increased volume and decreased pressure at the end of the propelling nozzle, there is rejection of heat at constant pressure. The Orpheus engine which is fitted in Kiran MkII jet aircraft is performing an excellent job as it is used for giving the training to the fighter pilots.
\end{abstract}

Keyword : Gas turbine, Turbo propeller, Compressor

\section{INTRODUCTION}

\section{A. Basic Theory and Principles of Propulsion}

At the point when an air ship is going through air in straight and level flight and at a steady evident velocity (TAS), the motors must create an all out push equivalent to the delay the flying machine as appeared in Fig.1.1 If the motor push surpasses the drag, the air ship will quicken, and if the drag surpasses the push, the airplane will back off[19],[21],[22].

Albeit an assortment of motor kinds are accessible for flying machine impetus, the push power should consistently originate from air or gas response powers regularly following up on the motor or propeller surfaces.

The two common methods of aircraft propulsion are:

a. The propeller engine powered by piston or gas turbine.

b. The jet engine.

Revised Manuscript Received on August 22, 2019.

N. Lenin Rakesh, Department of Mechanical Engineering, Bharath Institute of Higher Education and Research, Chennai, Tamilnadu, India. Email: leninrakesh@gmail.com

Sabarish R, Department of Mechanical Engineering, Bharath Institute of Higher Education and Research, Chennai, Tamilnadu, India. Email: sabarish5041@gmail.com

S. Karthikeyan, Department of Mechanical Engineering, Bharath Institute of Higher Education and Research, Chennai, Tamilnadu, India. Email: karthi.keyan5@yahoo.co.in
Rotary wing aircraft are powered by turbo shaft engines which produce shaft power to drive a gearbox and work on similar principles to gas turbine propeller engines (turboprops), except that all the available energy is absorbed by the turbine, with no residual jet thrust.

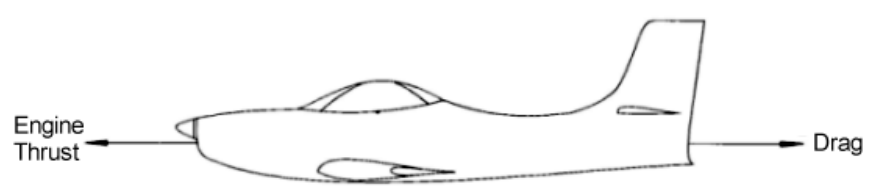

Figure - 1 Arrangements of Thrust and Drag Forces

\section{DESIGN PRINCIPLES}

\section{A. Propeller Engine}

With a propeller engine, the engine power produced drives a shaft which is connected to a propeller usually via a gearbox. The propeller cuts through the air accelerating it rearwards. The blade of a propeller behaves in the same way as the aerofoil of an aircraft; the air speeds up over the leading face of the propeller blade causing a reduced pressure with a corresponding increase of pressure on the rearward face. This leads to a net pressure force over the propeller where

Pressure $\times$ Area $=$ Force thus providing thrust, eg: Given: Net pressure of $40 \mathrm{kPa}\left(\mathrm{Pa}=\mathrm{N} / \mathrm{m}^{2}\right)$ and a Blade area of $1 \mathrm{~m}^{2}$

Thrust $=40 \mathrm{kPa}$ X $1 \mathrm{~m}^{2}=40 \mathrm{kN}$

With gas turbine powered propeller engines, a small amount of thrust is produced by the jet exhaust which will augment the thrust produced by the propeller.

An alternative method of calculating the thrust produced by a propeller is provided by Newton's laws of motion which give: Force $=$ Mass $\mathrm{X}$ Acceleration

Thrust $=$ Mass flow rate of air through Propeller $\times$ Increase in velocity of the air

$=\mathrm{Mx}\left(\mathrm{V}_{\mathrm{j}}-\mathrm{V}_{\mathrm{a}}\right)$

Where $\mathrm{M}=$ Mass flow rate of the air

$\mathrm{V}_{\mathrm{j}}=$ Velocity of slip stream

$\mathrm{V}_{\mathrm{a}}=$ Velocity of the aircraft (TAS)

This will give the same result as that given by the sum of pressure forces. In the case of the propeller, the air mass flow will be large, and the increase in velocity given to the air will be fairly small.

\section{B. Jet Engine}

In all cases of the jet engine, a high velocity exhaust gas is produced, the velocity of which, relative to the engine, is considerably greater than the TAS. Thrust is produced according to the equation:

Thrust $=\mathrm{Mx}\left(\mathrm{V}_{\mathrm{j}}-\mathrm{V}_{\mathrm{a}}\right)$ 
Where $V_{j}$ is now the velocity of the gas stream at the propelling nozzle. This represents a simplified version of the full thrust equation as the majority of thrust produced is a result of the momentum change of the gas stream.

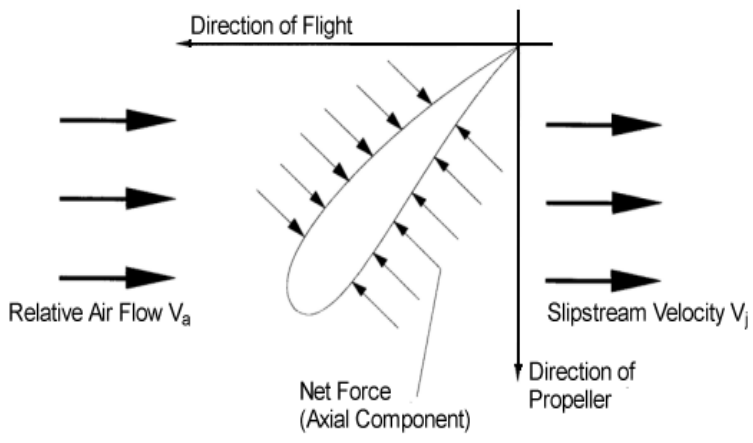

Figure 2 - Direction of Flight vs. Direction of Propeller

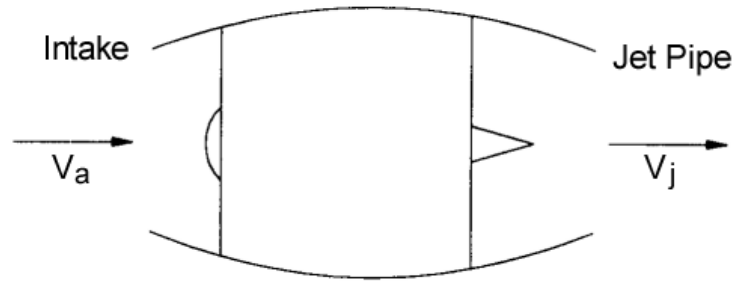

Figure 3 - Jet Thrust - Relative Velocities

\section{Power unit and working cycle of jet engine}

\section{Power Unit}

The aircraft is powered by an ORPHEUS-70105 engine. The engine is a straight flow turbo-jet type, fitted with a 7 -stage axial flow compressor and develops $4200 \pm 84$ Ibs/ $1909+38 \mathrm{~kg}$ static thrust at $9500 \mathrm{rpm}$ at sea level. This increases to a maximum at $10,000 \mathrm{ft}$, due to the characteristics of the high pressure fuel pump in the engine fuel system. Above this height the thrust developed reduces as altitude increases. The engine change unit includes air driven starter, switches for low-pressure fuel and oil pressure warning indicators and all engine driven accessories except the main electrical generator and hydraulic pump[14],[16],[18].

\section{Engine Working Cycle}

Air at atmospheric pressure is compressed adiabatically, during its passage across the compressor and diffuser, to approximately four atmospheres. The pressure and temperature increases and volume decreases at this stage. In the combustion chamber, heat is supplied at constant pressure there by considerably increasing the volume of air. Then during the passage of the gas stream through the rear end of the combustion chambers, stationary vanes, turbine and exhaust cone, there is adiabatic expansion, which is completed in the propelling nozzle with increased volume and decreased pressure. At the end of propelling nozzle, there is rejection of heat at constant pressure.

Air flowing through the engine follows a straight path. Air entering in to the air intake duct is directed by entry guide blades at the rear of the air intake casing into the compressor, where in temperature and pressure increases progres $\neg$ sively with its passage through the seven stages to the delivery casing. Air discharged from the delivery casing enters the combustion chambers, where it is mixed with the atomized fuel sprayed from the burners. Initially, the mixture is ignited by the igniter plugs. The continuous combustion inside the combustion chamber raises the temperature and velocity (but not the pressure) of the gas. Immediately after the combustion zone, air is introduced to reduce the gas temperature to a value compatible with the limits of the turbine blade mate $\neg$ rial from the combustion chambers, the velocity of the gas increases due to the nozzle effect between adjacent stator blades. A further increase in velocity occurs as the pressure and temperature fall during the passage through the turbine wheel blades. The high velocity gases impinging on the combined impulse and reaction type blades turn the turbine wheel. The power generated by the turbine is absorbed primarily in driving the compressor to pressurize the incoming air, only a small portion being utilized to drive the auxiliary equipment and accessories. On leaving the turbine, the velocity continues to increase and pressure and temperature falls, the ultimate velocity being reached as the gases pass out of the exhaust cone into the jet pipe.

\section{Working Cycle}

A gas turbine is basically a warmth motor utilizing air as a liquid to create push. The working cycle of the gas turbine is like that of a cylinder motor and both motor cycles have enlistment, pressure, ignition and fumes stages. Anyway a gas turbine can manage a lot bigger measures of vitality for a given size and weight, and it has the additional preferred position that the mechanical movement is consistent and totally rotational, while the cylinder motor uses a discontinuous responding movement which is changed over to revolving movement by methods for wrenches. In result the gas turbine runs all the more easily.

The gas turbine cycle can be spoken to by a temperature/entropy (T/S) outline. (Entropy is a proportion of turmoil; the more noteworthy the entropy or level of confusion in the gas, the less work can be extricated from it.) Referring to, Point 1 speaks to the passage to the blower; the air experiences adiabatic pressure along the line 1-2. Warmth is added to the air through consuming fuel which causes consistent weight warming along the line 2-3. Adiabatic development through the turbines, line 3-4, extricates vitality from the gas stream to drive the blower and perhaps a propeller, fan or rotor framework. 

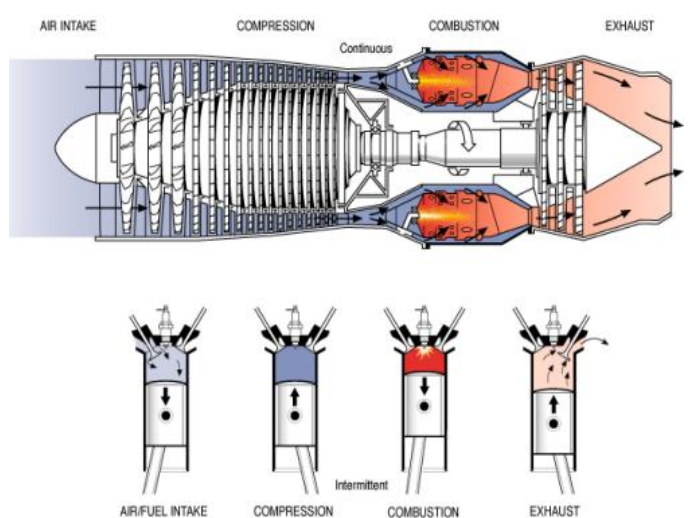

Figure 4 - Working Cycle

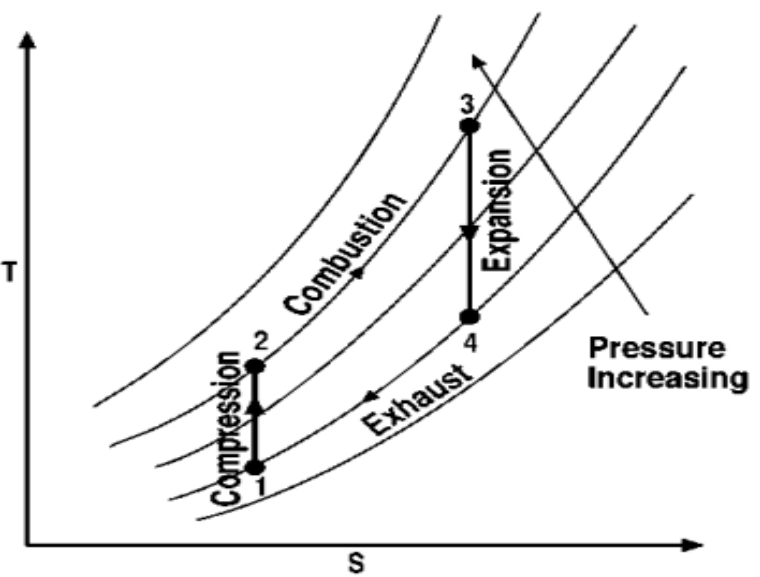

Figure 5 - Gas Turbine T-S Diagram

As the gas turbine motor is dependent upon warmth to grow the gases, the higher the temperature in the ignition stage the more prominent the development of the gases. Notwithstanding, the burning temperature must be restricted to a level that can be securely acknowledged by the materials utilized in the turbine and fumes parts. Figure demonstrates the gas move through a run of the mill gas turbine and furthermore gives agent esteems for temperature, gas speeds and weights[13],[15],[17].

\section{RESULT AND DISCUSSION}

\section{A. Performance}

The planned exhibition of an airplane motor is directed by the sort of tasks for which the air ship is expected. In spite of the fact that turbojet motors are evaluated in kilo-Newtons and turbo-propeller motors in kilo-watts, the two kinds are surveyed on the power delivered for a given weight, fuel utilization and frontal zone.

Since the push or shaft power created by the gas turbine is subject to the mass of air entering the motor, it pursues that the exhibition of the motor is impacted by such factors as forward speed, height, and climatic conditions. The effectiveness of the admission, blower, turbine and spout are straightforwardly influenced by these factors with a subsequent variety in push or shaft power delivered from the gas stream.

To expand range and mileage, the proportion fuel utilization to push or shaft power ought to be as low as could reasonably be expected. The proportion of fuel utilized in $\mathrm{kg} / \mathrm{h}$ per $\mathrm{KN}$ push, or $\mathrm{kW}$ of shaft control, is known as the particular fuel utilization (SFC). This is identified with the warm and propulsive proficiency of the motor.

\section{B. Comparison between Thrust KN (Force) and Shaft Power KW (Power):}

Since the turbojet motor is appraised in push and the turboprop motor is evaluated in identical shaft control, no immediate correlation can be utilized power change factors. Elements changing over the pole power formed into push, or the push created in the turbojet to shaft power might be utilized, in this way, changing over capacity to power or power to control[8],[10],[12].

In the SI arrangement of units, $1 \mathrm{~W}=1 \mathrm{Nm} / \mathrm{s}$, so the transformation of push to power requires the flying machine speed, in $\mathrm{m} / \mathrm{s}$, to be considered. For an air ship going at 150 $\mathrm{m} / \mathrm{s}$ (approx $290 \mathrm{kt}$ ), and the motor creating $40 \mathrm{KN}$, the push to control change is as per the following:

$40,000 \times 150=6,000,000=6,000 \mathrm{~kW}$

Now for a turboprop engine powering an aircraft at the same velocity, $150 \mathrm{~m} / \mathrm{s}$, with a propeller efficiency of $60 \%$, and producing $6,000 \mathrm{~kW}$ the engine rating will be:

$6,000 \times 100 / 60=10,000 \mathrm{~kW}$

Therefore, in an aircraft travelling at $150 \mathrm{~m} / \mathrm{s} 1 \mathrm{KN}$ of thrust = $250 \mathrm{KW}$ of power.

\section{Effect of Engine RPM on Gas Turbine Performance:}

Motor speed in cycles every moment has an extraordinary impact on the push created by a stream motor. Figure 5.1 demonstrates that almost no push is created at low rpm as contrasted and the push created at high motor rpm and that a given rpm change has more impact on pushed at higher motor rates than at lower motor rates. The heaviness of air siphoned by a blower is a component of its rpm. Reviewing the recipe

$$
\mathrm{Fn}=\mathrm{Wa}(\mathrm{V} 2-\mathrm{V} 1) / \mathrm{g}
$$

It is evident that increasing the weight of air being pumped will result in an increase in Fn or thrust. Engine speed may not be indiscriminately varied but must be controlled within very close limits. The conversion of fuel energy into gas energy is poor at low rpm, but improves rapidly to become most efficient between $90-100 \%$ rpm.

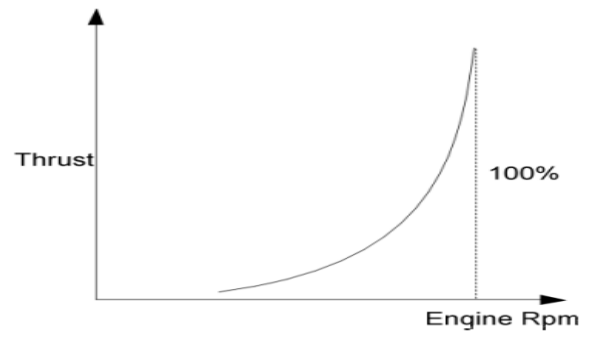

Figure 6 - Effect of Engine RPM on Thrust

D. Effect of Airspeed on Gas Turbine Performance: $\mathrm{F}_{\mathrm{n}}=\mathrm{W}_{\mathrm{a}}\left(\mathrm{V}_{2}-\mathrm{V}_{1}\right) / \mathrm{g}$ 
It demonstrates that any expansion in the forward speed of the plane will bring about a decline in push. The quicker the plane goes, the more prominent will be the underlying force of the air in connection to the motor (V1 expanding). Be that as it may, the stream spout speed is commonly fixed by the speed of sound. Clearly, the V2 - V1 contrast or force change will decrease as plane speed increments. This loss of push will be somewhat counterbalanced by the expansion in the $\mathrm{Wa}$ because of slam. Not as much push is recuperated because of the smash weight ascend as would appear to be shown on first assessment. At high plane speeds there is an extensive temperature ascend notwithstanding the ascent in weight. The genuine load of the wind current increment into the motor will be straightforwardly corresponding to the ascent in weight and conversely relative to the square foundation of the ascent in temperature[1],[3],[5].

From the recipe for push, it tends to be seen that push will shift with velocity:

Momentum Thrust $=\mathrm{W} x\left(\mathrm{~V}_{\mathrm{je}}-\mathrm{V}_{\mathrm{a}}\right)$

Where $\mathrm{W}=$ Mass Air Flow

$\mathrm{V}_{\mathrm{je}}=$ Gas Exit Velocity

$\mathrm{V}_{\mathrm{a}}=$ Gas Inlet Velocity

If the ram effect is discounted any increase in $\left(\mathrm{V}_{\mathrm{a}}\right)$ because of airspeed will result in a corresponding fall in thrust. However, for most fixed wing aircraft, the intake geometry is designed to take full advantage of the ram effect, and therefore as forward speed increases so will the mass flow of air inducted into the engine intake. The ram effect becomes apparent at about $300 \mathrm{KT}$, and it increases as airspeed increases until, at about $500 \mathrm{KT}$, the static thrust loss is fully recovered[2],[4],[6]. The thrust then continues to increase for a time, but eventually tends towards zero as the $\mathrm{Va}$ approaches the effective jet velocity $\left(\mathrm{V}_{\mathrm{je}}\right)$. The effect of increasing airspeed limits the use of a turbojet to Mach numbers of the order of 3.0. This limit can be extended slightly by afterburning which increases the value of $\mathrm{V}_{\text {je }}$

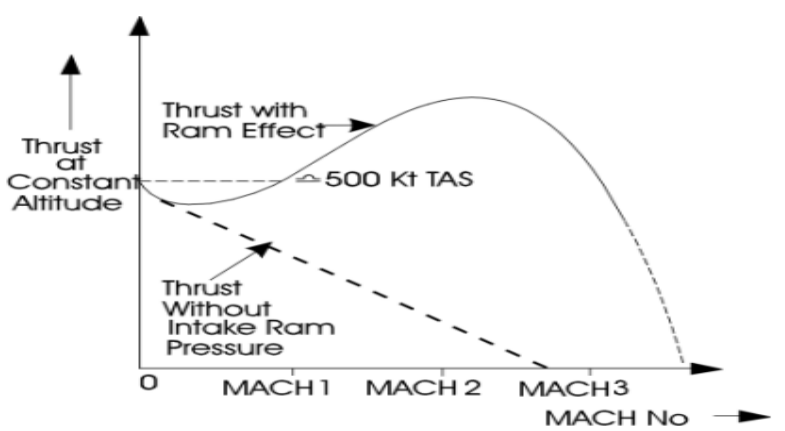

The advantage of the propeller over other forms of power plant at low speeds. Similarly, the turbofan engines can be seen to have advantages over the turbojet. The low bypass mixing turbojet bridges the gap between high bypass turbofans and pure turbojets. The mixing of the two gas streams is theoretically more efficient than exhausting the gas streams separately, but on high bypass turbofans it is almost impossible to achieve efficient mixing. Many other factors affect the choice of power plant, and the decision becomes a complex one, often with no clear cut answer[7],[9],[11].

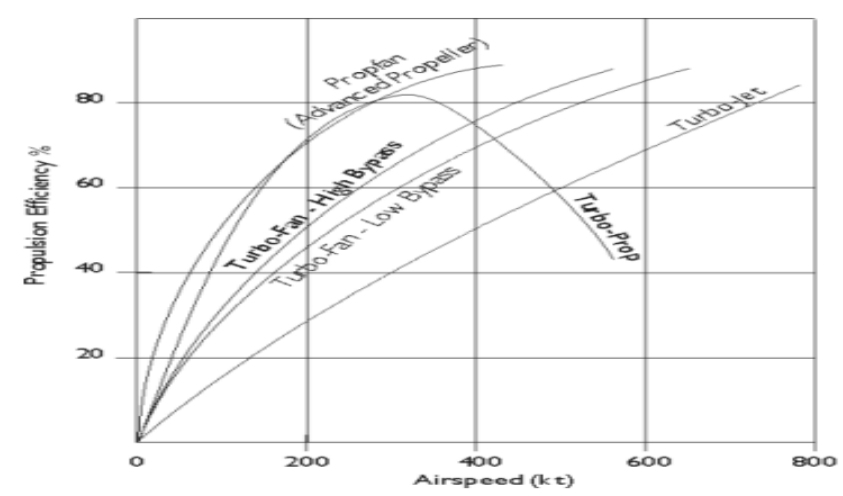

Figure 8 - Comparison of Propulsive efficiencies

\section{CONCLUSION}

The presentation of a fly motor relies upon the mass wind stream (mf), weight, elevation, temperature and climatic conditions.

Motor speed (in rpm) greatly affects the push created by fly motor. Almost no push is created at low rpm as contrasted and the push created at high rpm. Along these lines, a non-direct relationship exist between motor RPM and push.

Regardless, if motor works in air temperature more sultry than standard temperature (59 deg $\mathrm{F}=15 \mathrm{deg}$ centigrade), there will be less pushed delivered. Then again, motor activity in air temperature colder than standard day condition will create a more noteworthy than appraised push.

The higher the height, the less weight there is, bringing about reduction in push.

Thickness diminishes as stature (height) increments since it is straightforwardly corresponding to weight. As thickness diminishes push diminishes.

As velocity (speed of aero plane) increments there is lost (v2-v1) in light of the fact that v2 isn't expanding as v1. So there is decline in pushed so motor needs to work more.

A variable - territory exhaust spout framework increment the speed of the fumes to push the airplane quicker.

At the point when the situation of the trimmer in the stream pipe is transformed, it can decrease the region of the fumes cone in turns speed of airplane is upgraded by some degree (20\% of existing speed).

\section{REFERENCES}

1. Tatikonda, N.C. \& Naveenchandran, P. 2019, "The behaviour of a compression ignition engine under the influence of diesel and microalgae biodiesel blends", International Journal of Mechanical and Production Engineering Research and Development, vol. 9, no. 4, pp. 447-456.

2. Tatikonda, N.C. \& Naveenchandran, P. 2019, "An experimental assessment on the impact of injection pressure on 
the characteristics of a diesel engine powered with the blend of diesel and microalgae biodiesel", International Journal of Engineering and Advanced Technology, vol. 8, no. 6, pp. 3284-3291.

3. Karthikeyan, S., Raman Balasubramanian, S.R., Ramesh, B., Raghul, S. \& Sathish Kumar, S. 2019, "The automatic solar tracker chronicles", International Journal of Recent Technology and Engineering, vol. 8, no. 1, pp. 312-315.

4. Hema, R., Sundararajan, M. \& Balaji, S. 2019, "Smartphone control robot with automatic firing gun", International Journal of Innovative Technology and Exploring Engineering, vol. 8, no. 9 Special Issue 3, pp. 625-627.

5. Saritha, B., Chockalingam, M.P. \& Aswathy, M. 2019, "Degradation of anionic dye using Fe/Tio2 composite by photocatalysis", International Journal of Innovative Technology and Exploring Engineering, vol. 8, no. 9 Special Issue 3, pp. 788-791.

6. Saritha, B., Maria Subashini, L. \& Aswathy, M. 2019, "Utilization of spent coffee grounds for compost production", International Journal of Innovative Technology and Exploring Engineering, vol. 8, no. 9 Special Issue 3, pp. 908-910.

7. Fernando, J.K., Meikandaan, T.P. \& Hemapriya, M. 2019, "Better utilisation of bottom ash in coal fired thermal power station", International Journal of Innovative Technology and Exploring Engineering, vol. 8, no. 9 Special Issue 3, pp. 898-900.

8. Kumar, K.S., Kiruthiga, K. \& Thendral, S. 2019, "Experimental analysis on fractional substitution of bond by utilizing rice husk cinder", International Journal of Innovative Technology and Exploring Engineering, vol. 8, no. 9 Special Issue 3, pp. 1163-1165.

9. Vignesh, P., Madan, P., Mohankumar, D. \& Naveenchandran, P. 2019, "Optimization of four stroke c.i. engine performance by using statistical techniques (mathematical method)", International Journal of Recent Technology and Engineering, vol. 8, no. 2, pp. 1685-1691.

10. Bharanidharan, S., Sathiyamurthy, K. \& Sheeba, B. 2019, "Using co-precipitation method determining synthesis and characterization of fe doped zinc oxide nanoparticles", International Journal of Innovative Technology and Exploring Engineering, vol. 8, no. 9 Special Issue 3, pp. 705-707.

11. Jeevanandan, D. \& Vino, J.A. 2019, "Heat recovery from boiler blowdown water by using heat exchanger in thermal power plant", International Journal of Mechanical and Production Engineering Research and Development, vol. 9, no. 3, pp. 219-222.

12. Rakesh, N.L., Balambica, V. \& Kannan, S. 2019, "Biogas extraction from waste orange peel by digestion process", International Journal of Mechanical and Production Engineering Research and Development, vol. 9, no. 3, pp. 323-330.

13. Meenakshi, C.M. \& Krishnamoorthy, A. 2019, "The mechanical characterization of mono and hybrid fiber reinforced composites using experimental and finite element analysis methods", International Journal of Mechanical and Production Engineering Research and Development, vol. 9, no. 3, pp. 189-196.

14. Mohankumar, D., Prem Jayakumar, M., Sabarsish, R. \& Naveen Chandran, P. 2019, "Modeling and experimental investigation on centrifugal blower by computational fluid dynamics", International Journal of Mechanical and Production Engineering Research and Development, vol. 9, no. 3, pp. 331-340.

15. Balambica, V., Deepak, V. \& Kumar, S. 2019, "Design and efficiency of an asymmetric gear", International Journal of Mechanical and Production Engineering Research and Development, vol. 9, no. 3, pp. 223-230.

16. Manavalan, S., Balakrishnan, G. \& Ramasubramaniam, S. 2019, "An effect of cobalt oxide nano additive with biodiesel blends using cidi diesel engine", International Journal of Mechanical and Production Engineering Research and Development, vol. 9, no. 3, pp. 211-218.

17. Golden Renjith Nimal, R.J., Sivakumar, M. \& Esakkimuthu, G. 2019, "An investigation on mechanical properties and microstructure of $\mathrm{mg} / \mathrm{al}$ alloys using $\mathrm{zn}$ interlayer during diffusion bonding", International Journal of Mechanical and Production Engineering Research and Development, vol. 9, no. 3, pp. 125-130.

18. Hariharan, R., Raja, R. \& Vasu, S. 2019, "Mechanical and tribological behaviour of thin tan coating produced on AISI 1018 substrate by DC magnetron sputtering", International Journal of Recent Technology and Engineering, vol. 7, no. 6, pp. 591-598

19. Manavalan, S., Rai, R., Kumar, R.R., Chaudhary, R.K. \& Chaudhary, S.K. 2019, "Impact of modified piston - A review", International Journal of Recent Technology and Engineering, vol. 8, no. 6, pp. 616-620.

20. Manavalan, S., Gopi, A., Arivarasu, J., Abishek Ahi, A. \& Chandru, S 2019, "Review on ceramic disc brake system", International Journal of Recent Technology and Engineering, vol. 7, no. 6, pp. 612-615.
21. Sabarish, R. \& Jeya Kumar, M.P. 2019, "The design and analysis of piston - Steady state thermal analysis using "ansys", International Journal of Mechanical and Production Engineering Research and Development, vol. 9, no. 3, pp. 197-204.

22. Ravi, D. 2019, "CFD simulation of solar loading in car", International Journal of Mechanical and Production Engineering Research and Development, vol. 9, no. 3, pp. 231-236.

\section{AUTHORS PROFILE}

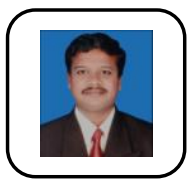

N. Lenin Rakesh Assistant Professor, Department of Mechanical Engineering, Bharath Institute of Higher Education and Research, Chennai, India.

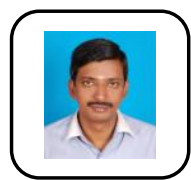

Sabarish R Assistant Professor, Department of Mechanical Engineering, Bharath Institute of Higher Education and Research, Chennai, India.

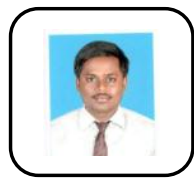

S. Karthikeyan Assistant Professor, Department of Mechanical Engineering, Bharath Institute of Higher Education and Research, Chennai, India. 